\title{
COMPETENCY V: DEVELOPMENTAL PRACTICE METHODS
}

In these days of "evidence based practice", we all look to see if our work is indeed based on some kind of factual base that it will indeed have a positive effect. The 'evidence' is still out on what actually comprises 'evidence', since many still feel that direct experience that has been reflected upon and thoughtful applications based on respected theories also are can serve as the basis for practice. Fortunately our field accepts useful information from multiple methods and multiple sources. As well, when it comes right down to it, it is difficult to classify articles as 'research', 'practice' and 'classic'. Many valuable pieces contain aspects of all three, although it is true for some that one form may predominate. This is true of the pieces selected, after a great deal of deliberation, for inclusion in the Developmental Practice Methods section.

Classic: Maier, H. (1994). Attachment development is "In". Journal of Child and Youth Care, 9(1), 25-51.

Research: Jones, K., \& Perkins, D. (2006). Youth and adult perceptions of their relationships within community-based programs. Youth and Society, 38(1), 90-109.

Practice: Schneider-Muñoz, A. (1986). Strategic activity programming for emotionally disturbed children and adolescents. Journal of Child and Youth Care Work, 4, 71-79.

\section{CLASSIC}

Nobody could be more classic than Henry Maier. His humanity and essential understanding of the true meaning of child and youth care work has helped lay the foundation for this field whose mission is to provide care and thus enable youngsters to develop positively. Child and youth work more than any other human service field or profession is responsible for ensuring the quality of daily life in the milieu, providing the environment, relationships, and activities, among other variables that promote healthy development.

Today the disruptions that occur in many youngsters' lives early on as their families struggle with a multitude of problems have the potential to disrupt their ability to form the most crucial psychological attribute-attachment. Our beloved Henry reminds us of this - and solidly establishes the role of our field in ensuring that attachment occurs for all the children and youth with whom we work.

\section{RESEARCH}

This empirical study utilized formal data gathering methods to assess youth and adult involvement and youth-adult interaction in a variety of community programs. It has strong implications for practice and implementing the community aspect including relationships with adults that is so key in an ecological approach to child and youth work. Specifically, the authors draw upon intergroup contact theory in building the case that youth participation and leadership, rather than adultdriven collaborations, are critical to youth involvement in community. That there is 
little in our literature on youth relationships in the community further supports the selection of this article.

\section{PRACTICE}

Many in the field have felt for years that the provision of stimulating, engaging, challenging and rich activities, while recognized as a function of the child and youth care field, has been its "weakest link". Even where there is understanding of the development benefits of activities, child and youth practitioners somehow have difficulty implementing an activity program in their settings. The Schneider-Muñoz article, both a classic and a practice piece, gets right to the point. It's full of wonderful ideas that child and youth workers can use to transform their milieu from one of boredom and acting out, to one in which children and workers interact over play, projects, and hobbies. Both the activities suggested and the strategies for designing and implementing them, can help strengthen activities in the milieu and promote the positive development of children and youth.

\section{Developmental Practice Methods Domain Editors}

Karen VanderVen, PhD, Professor Emerita

University of Pittsburgh

Dana Fusco, $P h D$

York College

Varda Mann-Feder, DEd

Concordia University 